is evidence that haemorrhagic disease is several times commoner in African than in white infants (Lanzkowsky et al., 1967). All our 13 cases were in white infants, and in each one the vacuum extractor had been used. No cases of subaponeurotic haemorrhage have been seen in our hospital in over 12,000 deliveries by other methods. It is well recognized that the incidence of haemorrhagic disease of the newborn does not correlate closely with the prothrombin time. Other factors, such as trauma, or temporary hepatic insufficiency from hypoxia, infection, or immaturity, play a part.

While the relationship of subaponeurotic haemorrhage to vacuum extractor in our hospital can leave little room for doubt that the trauma inflicted on the soft tissues of the foetal scalp is an important aetiological factor, the fact that in seven of the nine cases in which it was measured the thrombotest activity was less than $15 \%$ indicates the even greater influence of the blood-clotting mechanism. Indeed, it is clear that delivery by vacuum extraction when associated with a thrombotest activity below $10 \%$ constitutes a grave risk of fatal or dangerous haemorrhage in the baby. It was a disappointment to us that the routine administration of phytomenadione by intramuscular injection to every infant born by vacuum extractor did not abolish subaponeurotic haemorrhage, or in fact prevent fatal haemorrhage, in one infant. As paediatricians we are not competent to pronounce on the merits of delivery by vacuum extractor in contrast to other instrumental methods, and several experienced obstetricians have written enthusiastically on its use (Malmström, 1964 ; Willocks, 1962 ; Chalmers, 1964).

We think it appropriate, however, to present the undesirable effects which we have encountered. We now believe that, if possible, the thrombotest should be performed as soon after birth as possible in every infant on whom the vacuum extractor has been used. As our experience indicates that the action of vitamin $K_{1}$ is not rapid enough to prevent massive bleeding consideration might be given to the transfusion of fresh frozen plasma, $10 \mathrm{ml} . / \mathrm{kg}$., in every infant born by vacuum extraction and with a thrombotest activity at or below $10 \%$. This policy has already been shown to lessen the risk of death from intracranial haemorrhage in infants of low birth weight with low thrombotest levels (Gray et al., 1968).

\section{REFERENCES}

Aballí, A. J., Banús, V. L., de Lamerens, S., and Rozengvaig, S. (1959).

American fournal of Diseases of Children, 97, 524.
Barrow, E., and Peters, R. L. (1968). South African Medical fournal, 42, 265.

Chalmers, J. A. (1964). British Medical fournal, 1, 1216.

Gray, O. P., Ackerman, A., and Fraser, A. J. (1968). Lancet, 1, 545. American fournal of Diseases of Children, 108, 413 .

Lange, P. (1964). Acta Obstetrica et Gynecologica Scandinavica, 43, Supplement No. 1 , p. 53.

Lanzkowsky, P., Joffe, H. S., Levy, S., Nossel, H. L., and Mibashan, R. S. (1967). South African Medical fournal, 41, 1039

Leonard, S., and Anthony, B. (1961). American fournal of Diseases of Children, 101, 170 .

Malmström, T. (1964). Acta Obstetrica et Gynecologica Scandinavica, 43, Supplement No. 1 , p. 5.

Pachman, D. J. (1962). Pediatrics, 29, 907.

Rausen, A. R., and Diamond, L. K. (1961). American fournal of Diseases of Children, 101, 164.

Robinson, R. J., and Rossiter, M. A. (1968). Archives of Diseases in Childhood, 43, 684 .

Valentine, G. H. (1964). Canadian Medical Association fournal, 91, 177. Van der Horst, R. L. (1963). Archives of Diseases in Childhood, 38, 280.

Willorks, J. (1962). Fournal of Obstetrics and Gynaecology af the British Commonwealth, 69, 266.

\title{
Comparison of Birth Weight/Gestation Distribution in Cases of Stillbirth and Neonatal Death According to Lesions Found at Necropsy
}

\author{
JEAN FEDRICK,* M.A.
}

British Medical fournal, 1969, 3, 745-748

\begin{abstract}
Summary : The birth weight/gestation distribution of a $\checkmark$ large series of cases of perinatal death has been analysed according to the lesion (or lesions) present at necropsy. Among the lesions associated with low gestation babies dying with hyaline membranes have a much higher mean birth weight for gestation than either the babies with intraventricular haemorrhage or " no cause found." Among infants dying of intrapartum asphyxia or cerebral birth trauma it was found that those who were stillborn with trauma had, at term, a significantly higher mean birth weight than the control livebirths, and that, at all gestations, the stillbirths with trauma were, on average, heavier than the babies dying neonatally with this lesion. Cases of intrapartum asphyxia were smaller than the stillbirths with trauma, but those dying during the second stage of labour were larger than those dying during the first stage.
\end{abstract}

Cases of intrauterine pneumonia-that is, stillbirths and first-day deaths-were also shown to be larger for length of gestation than cases of extrauterine pneumonia-that

* Honorary Research Assistant, Department of Human Genetics and Biometry, University College London, London W.C.1. is, deaths between the second and the 28th day. The cases with haemorrhagic pneumonia, however, were, at least at term, smaller than the cases of extrauterine pneumonia, and cases of massive pulmonary haemorrhage showed evidence of growth retardation at all gestations.

\section{Introduction}

Though many authors have studied the birth weights or, more rarely, the periods of gestation of a series of cases in which perinatal death occurred, only occasionally has the combination of birth weight with gestation been examined. As this is a valuable indication of whether the foetus or infant concerned was in "distress" before the actual processes of labour and delivery began (Gruenwald, 1963), the unique data of the British Perinatal Mortality Survey have been analysed with regard to certain lesions found at necropsy.

\section{Material and Methods}

The data used are those of the 7,117 singleton stillbinths and neonatal deaths occurring in March, April, and May 1958 
throughout England, Scotland, and Wales, compared with all the 16,994 singleton births delivered in the same regions during the first week of March 1958, and known hereafter as the control population. A detailed description of the data has been given by Butler and Bonham (1963) and Butler and Alberman (1969). From the 7,117 deaths have been excluded all cases with a major congenital malformation-that is, all cases where the malformation was judged to have been a cause of deathtogether with all cases showing evidence of rhesus isoimmunization and all macerated stillbirths.

The classifications of cerebral birth trauma, intraventricular haemorrhage, and asphyxia were largely based on reports of macroscopic pathological examinations, whereas the classifications of hyaline membranes, massive pulmonary haemorrhage, haemorrhagic pneumonia, pneumonia, and "no cause found" were accepted only after the lung histology had been reassessed for consistency of reporting in London.

For the purposes of this paper only those babies whose birth weight (recorded in ounces) and the period of gestation (recorded in days from the beginning of the last menstrual period) were known accurately are included. Those cases which had two or more coexisting lesions appear in each of the relevant categories, with the exception of certain combinations: those which showed microscopical evidence of a pulmonary infection coexisting with a massive pulmonary haemorrhage have been placed in the category haemorrhagic pneumonia only, and those where there was evidence of cerebral birth trauma coexisting with signs of asphyxia appear in the trauma column only. In addition the cases of trauma have been divided according to whether death occurred before or after delivery, and those of asphyxia according to whether death occurred during the first or second stage of labour. Among deaths with evidence of pulmonary infection I have distinguished between those where the infection was probably acquired in utero-the stillbirths and first-day deaths (Ahvenainen, 1953 ; Avery et al., 1953)-and those where the infection was more likely to have been acquired neonatallythe deaths which occurred between the 2 nd and 28 th days.

\section{Results and Comment}

A preliminary analysis of the gestational distributions of the lesions (Table I) shows that, as might have been expected, the lesions of predominantly short gestation are hyaline membranes, intraventricular haemorrhage, and no cause found, whereas massive pulmonary haemorrhage is mainly prevalent among babies delivered at term. The other lesions are also frequently found among postmature births, this being especially true of intrauterine pneumonia and asphyxia during the second stage of labour.

Table I.-Percentage Gestational Distribution of Each Lesion

\begin{tabular}{|c|c|c|c|c|}
\hline \multirow{2}{*}{\multicolumn{2}{|c|}{ Lesion }} & \multicolumn{3}{|c|}{ Gestation (Weeks) } \\
\hline & & $\leqslant 37$ & $38-41$ & $42+$ \\
\hline 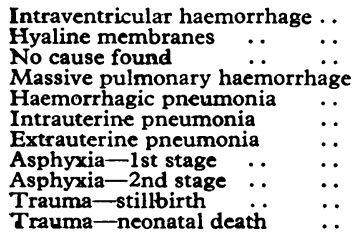 & $\begin{array}{l}\because \\
\because \\
\because \\
\because \\
\because \\
\because \\
\because \\
\therefore\end{array}$ & $\begin{array}{l}89 \cdot 3 \\
88 \cdot 7 \\
81 \cdot 3 \\
45 \cdot 1 \\
50 \cdot 0 \\
39 \cdot 3 \\
43 \cdot 3 \\
49 \cdot 5 \\
24 \cdot 6 \\
21 \cdot 7 \\
32 \cdot 6\end{array}$ & $\begin{array}{r}7 \cdot 8 \\
8 \cdot 6 \\
15 \cdot 4 \\
51 \cdot 0 \\
36 \cdot 8 \\
42 \cdot 7 \\
42 \cdot 1 \\
37 \cdot 6 \\
57 \cdot 7 \\
65 \cdot 3 \\
53 \cdot 3\end{array}$ & $\begin{array}{r}2.9 \\
2 \cdot 7 \\
3 \cdot 3 \\
3.9 \\
13 \cdot 2 \\
18 \cdot 0 \\
14 \cdot 6 \\
12 \cdot 9 \\
17 \cdot 7 \\
13 \cdot 0 \\
14 \cdot 0\end{array}$ \\
\hline Control livebirth ... & .. & $8 \cdot 5$ & $79 \cdot 3$ & $12 \cdot 3$ \\
\hline
\end{tabular}

In Table II are contrasted the mean birth weights (and their standard errors), within gestational groups, of the lesions in infants with predominantly short gestations. It can be seen from Fig. 1 that, whereas the cases of hyaline membranes have a mean birth weight, at pre-term gestations, slightly less than that for the control livebirths-a result confirmed by deSa (1969) - the cases of intraventricular haemorrhage have a much lower mean birth weight. This is also true of the cases of no cause found ; and it is interesting to note that Fairweather et al. (1966) remarked especially on the low birth weights found in babies in this category.

TABLE II.-Mean Birth Weight (in grammes) and Standard Error of Babies Having Lesions Associated with Extreme Immaturity

\begin{tabular}{|c|c|c|c|c|}
\hline $\begin{array}{l}\text { Gestation } \\
\text { (Weeks) }\end{array}$ & $\underset{\text { Membranes }}{\text { Hyaline }}$ & $\begin{array}{c}\text { Intraventricular } \\
\text { Haemorrhage }\end{array}$ & $\begin{array}{l}\text { No Cause } \\
\text { Found }\end{array}$ & $\begin{array}{c}\text { Control } \\
\text { Livebirths }\end{array}$ \\
\hline $\begin{array}{l}<28 \\
28-9 \\
30-1 \\
32-3 \\
34-5 \\
36-7 \\
38 \\
39-41 \\
42+\end{array}$ & $\begin{array}{r}961 \pm 54(27) \\
1,200 \pm 45(35) \\
1,603 \pm 44(56) \\
1,923 \pm 47(52) \\
2,316 \pm 83(37) \\
2,194 \pm \pm 127(21) \\
1,960 \pm 209(7) \\
2,716 \pm \pm 131(15) \\
3,418 \pm 336(7)\end{array}$ & $\begin{array}{r}836 \pm 51(26) \\
1,066 \pm 57(22) \\
1,299 \pm 77(16) \\
1,753 \pm 122(17) \\
{[2,012 \pm 197](4)} \\
1,956 \pm 167(7) \\
{[2,778 \pm 269](4)} \\
{[2,934 \pm 88](4)} \\
{[2,816 \pm 293](3)}\end{array}$ & $\begin{array}{r}745 \pm 37(31) \\
1,106 \pm 68(12) \\
1,432 \pm 161(12) \\
1,616 \pm 141(6) \\
{[1,467 \pm 187](4)} \\
2,038 \pm 343(9) \\
2,087 \pm 230(5) \\
2,545 \pm 219(9) \\
{[3,770 \pm 241](3)}\end{array}$ & $\begin{array}{r}970 \pm 12(14) \\
1,401 \pm 23(18) \\
1,833 \pm 18(35) \\
2,237 \pm 13(75) \\
2,630 \pm 8(193) \\
2,971 \pm 3(878) \\
3,153 \pm 1(1,410) \\
3,406 \pm 1(9,949) \\
3,530 \pm 2(1,761)\end{array}$ \\
\hline
\end{tabular}

Numbers of cases involved are shown in parentheses. Brackets indicate that numbers are not large enough to be valid.

At longer gestations the figures for hyaline membranes are somewhat misleading: a study of organ weights (Butler and Alberman, 1969 ; Fedrick and Butler, 1969b) has shown that the babies in this series born after 36 weeks who appear to be growth-retarded are mostly cases of mistaken gestation. In addition there appear to be a group of babies delivered at term, of normal birth weight, which have a coexisting pulmonary infection and are thought to belong to a different pathological entity (Wade-Evans, 1961). In contrast, when the organ weights of those babies with intraventricular haemorrhage and no cause found who were delivered at term were examined they were seen on the whole to be typical of the growthretarded infant.

Table III shows the mean birth weights of babies with pulmonary lesions more associated with term deliveries (intrauterine, extrauterine, and haemorrhagic pneumonia, and massive pulmonary haemorrhage). It can also be seen from Fig. 2 that, compared with the control livebirths, the babies with massive pulmonary haemorrhage are of very low mean birth weight at all gestations after the 30th week, whereas babies with haemorrhagic pneumonia are not quite so growth-retarded. The differences between the cases of intrauterine and extrauterine pneumonia become apparent only at term, when it can be seen that the latter are on average some $400 \mathrm{~g}$. smaller than the former (Fig. 3) but are nevertheless larger than the cases with haemorrhagic pneumonia.

TABLE III.-Mean Birth Weight and Standard Error of Babies Dying with Intrauterine, Extrauterine, and Haemorrhagic Pneumonia and Massive Pulmonary Haemorrhage

\begin{tabular}{c|c|c|c|c}
\hline $\begin{array}{c}\text { Gesta- } \\
\text { tion } \\
\text { (Weeks) }\end{array}$ & $\begin{array}{c}\text { Intrauterine } \\
\text { Pneumonia }\end{array}$ & $\begin{array}{c}\text { Extrauterine } \\
\text { Pneumonia }\end{array}$ & $\begin{array}{c}\text { Haemorrhagic } \\
\text { Pneumonia }\end{array}$ & $\begin{array}{c}\text { Massive } \\
\text { Pulmanary } \\
\text { Haemorrhage }\end{array}$ \\
\hline$<28$ & $841 \pm 70(15)$ & $851 \pm 42(9)$ & {$[1,304 \pm 213](3)$} & $-(0)$ \\
$28-9$ & $1,202 \pm 88(10)$ & $1,091 \pm 155(6)$ & {$[1,200 \pm 000](1)$} & $1,271 \pm 62(6)$ \\
$30-1$ & $1,353 \pm 166(7)$ & $1,673 \pm 225(6)$ & {$[1,538 \pm 131](4)$} & $1,400 \pm 122(5)$ \\
$32-3$ & $2,098 \pm 76(6)$ & $1,661 \pm 93(14)$ & $1,862 \pm 281(6)$ & $1,474 \pm 67(9)$ \\
$34-5$ & $2,141 \pm 160(15)$ & $2,323 \pm 111(16)$ & $2,299 \pm 122(11)$ & $1,851 \pm 152(13)$ \\
$36-7$ & $2,559 \pm 158(19)$ & $2,274 \pm 183(20)$ & $2,117 \pm 237(9)$ & $1,806 \pm 136(13)$ \\
38 & $3,053 \pm 186(14)$ & $2,902 \pm 141(8)$ & $2,769 \pm 162(9)$ & $2,477 \pm 132(13)$ \\
$39-41$ & $3,435 \pm 85(64)$ & $2,985 \pm 80(61)$ & $2,660 \pm 146(16)$ & $2,677 \pm 95(39)$ \\
$42+$ & $3,742 \pm 92(33)$ & $3,371 \pm 135(24)$ & $3,367 \pm 269(9)$ & {$[2,821 \pm 117](4)$} \\
\hline
\end{tabular}

TABLE IV.-Mean Birth Weight and Standard Error of Babies Dying with Intrapartum Asphyxia and Cerebral Birth Trauma

\begin{tabular}{c|c|c|c|c}
\hline $\begin{array}{c}\text { Gesta- } \\
\text { tion } \\
\text { (Weeks) }\end{array}$ & \multicolumn{2}{|c|}{ Intrapartum Asphyxia } & \multicolumn{2}{|c}{ Cerebral Birth Trauma } \\
\cline { 2 - 3 } & 1st Stage & 2nd Stage & Stillbirths & Neonatal Deaths \\
\hline$<28$ & {$[1,304 \pm 311](2)$} & $-(0)$ & {$[964 \pm 000](1)$} & $1,092 \pm 127(6)$ \\
$28-9$ & $1,407 \pm 178(14)$ & {$[1,219 \pm 43](3)$} & {$[2,211 \pm 765](2)$} & $1,298 \pm 49(5)$ \\
$30-1$ & $1,418 \pm 83(21)$ & $1,590 \pm 130(10)$ & {$[723 \pm 156](2)$} & $1,520 \pm 161(10)$ \\
$32-3$ & $1,760 \pm 68(27)$ & $2,131 \pm 195(6)$ & $2,197 \pm 226(8)$ & $2,045 \pm 74(8)$ \\
$34-5$ & $2,124 \pm 111(31)$ & $2,282 \pm 82(12)$ & $2,180 \pm 262(10)$ & $2,365 \pm 172(12)$ \\
$36-7$ & $2,513 \pm 84(43)$ & $2,610 \pm 137(19)$ & $2,606 \pm 160(12)$ & $2,722 \pm 120(19)$ \\
38 & $2,984 \pm 137(21)$ & $3,019 \pm 137(19)$ & $3,087 \pm 165(10)$ & $3,198 \pm 132(11)$ \\
$39-41$ & $3,146 \pm 59(84)$ & $3,372 \pm 77(98)$ & $3,527 \pm 65(95)$ & $3,204 \pm 72(87)$ \\
$42+$ & $3,238 \pm 93(36)$ & $3,538 \pm 109(36)$ & $3,735 \pm 118(21)$ & $3,675 \pm 85(26)$ \\
& & & &
\end{tabular}


In Table IV are contrasted the cases of intrapartum asphyxia and cerebral birth trauma. It will be seen that at all gestations where the numbers of cases are large enough to be valid the cases in which death from asphyxia occurred during the first stage of labour were slightly smaller than those in which death occurred during the second stage. Furthermore, at least among term births, the stillborn babies with trauma were larger than the cases of intrapartum asphyxia, but that the cases of neonatal death with trauma tended to be slightly smaller than the stillborn with this lesion.
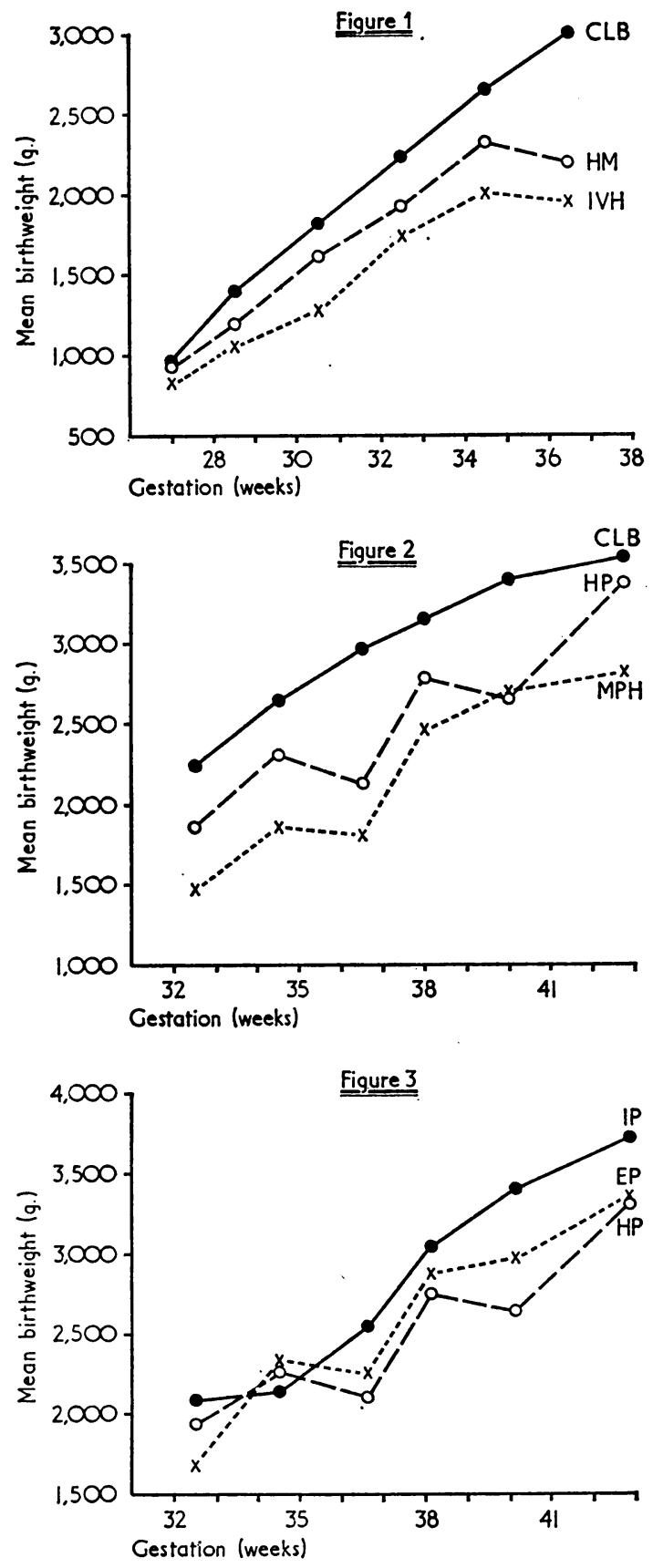

FIG. 1.-Mean birth weight of babies dying with hyaline membranes (HM) and intraventricular haemorrhage (IVH) com-
pared with the control livebirths (CLB). FIG. 2.-Mean birth weight of babies dying with haemorrhagic pneumonia (HP) and massive pulmonary haemorrhage (MPH) compared (HP) and massive pulmonary haemorr hage (MPH) compared with the control livebirths (CLB). FIG. 3.--Mean birth weigh haemorrhagic pneumonia (HP).

Since the largest numbers of cases are obtained in the gestational group 39-41 weeks, it is of value to compare the mean birth weights within this group for each series. These are depicted in Fig. 4 (the values for hyaline membranes and intraventricular haemorrhage having been omitted-the former for reasons given above and the latter because of the small number of cases. The diagram shows clearly that among term deliveries the cases of no cause found are of very low mean birth weight, as also are those of haemorrhagic pneumonia and massive pulmonary haemorrhage.

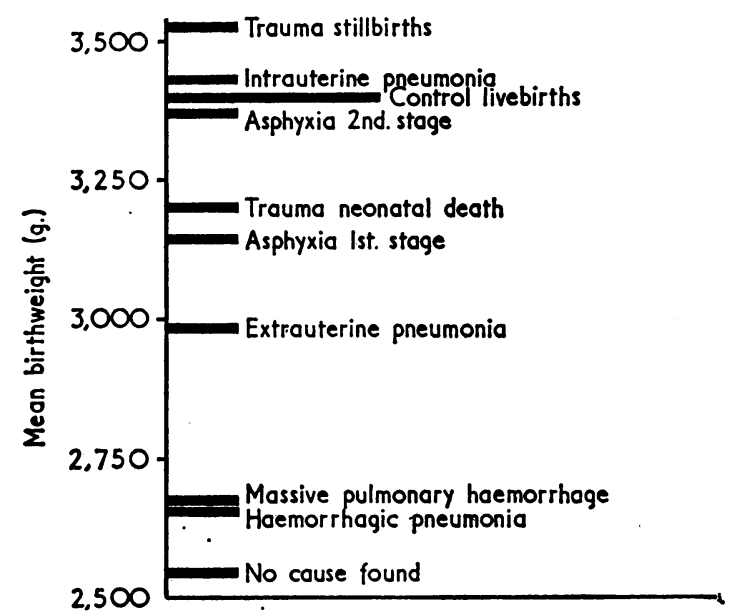

FIG. 4.-Relative mean birth weights of babies delivered between 39 and 41 weeks according to the lesions present, compared with the control livebirths.

In contrast, the cases of intrauterine pneumonia and asphyxia during the second stage are of about the same mean birth weight as the control livebirths, whereas the cases of trauma neonatal death, asphyxia in the first stage, and (especially) extrauterine pneumonia are of much lower mean birth weight. In contrast, the stillbirths with trauma have a significantly higher mean birth weight than the control livebirths.

\section{Discussion}

According to Gruenwald (1965), growth retardation is the result of chronic foetal distress apparently caused by a variety of conditions. It has been positively correlated with low maternal height (Dawkins, 1965 ; Schutt, 1965 ; Dolezalova and Dolezal, 1967) and maternal weight (Dolezalova and Dolezal, 1967), though Räihä (1967) stated that these correlations are due to the small maternal heart volume of mothers prone to delivery of growth-retarded infants. Correlations have also been found with maternal smoking (Mitchell and Farr, 1965 ; Ounsted, 1965 ; Butler and Alberman, 1969), severe maternal malnutrition (Smith, 1947), low social class (Dawkins, 1965 ; Ounsted, 1965 ; Schutt, 1965), primiparity (North, 1966); maternal megaloblastic anaemia (Stallworthy and Bourne, 1966) ; chronic nephritis (Schutt, 1965), as well as with severe toxaemia (Dawkins, 1965 ; Gruenwald, 1965 ; MacGillivray, 1965 ; Dolezalova and Dolezal, 1967). Nevertheless, as Walker (1965) has pointed out in his study of babies of birth weight less than $2,500 \mathrm{~g}$. delivered at term, there is no apparent clinical cause for the growth retardation in about half of the cases. Benirshke and Driscoll (1967) stated that the placenta of growth-retarded babies is usually small for the gestational age, but that there seems to be no other uniform distinction between the placentas of these infants and those of normal weight for their gestation. Dolezalova and Dolezal (1967), however, found an increased incidence of placental anomalies among the cases in their series.

The lesions considered in this paper fall into two main categories: (1) the lesions of extreme immaturity-hyaline membranes, intraventricular haemorrhage, and no cause found; and (2) the lesions more often associated with delivery after 37 weeks. The latter category can itself be subdivided into 
those lesions acquired before or during labour-cerebral birth trauma, intrapartum asphyxia, and intrauterine pneumoniaand those which (though possibly connected with the foetal history before delivery) develop after delivery-extrauterine pneumonia, haemorrhagic pneumonia, and massive pulmonary haemorrhage.

\section{Lesions of Immaturity}

From the results presented above hyaline membranes are probably not primarily associated with growth retardation at those gestations where it is most prevalent. Since it has often been observed that growth retardation can be caused by severe maternal toxaemia (Dawkins, 1965 ; Gruenwald, 1965 ; MacGillivray, 1965), it is relevant to note that it has been shown (Fedrick and Butler, 1969b) that severe pre-eclampsia in the mother does not predispose per se to a death with hyaline membranes. On the other hand, the finding that babies with intraventricular haemorrhage are, on the whole, small for their period of gestation agrees with the finding that their mothers have a greatly increased incidence of severe toxaemia (Fedrick and Butler, 1969a). Thus it can be concluded, with some degree of confidence, that the baby with hyaline membranes is not as likely to have suffered from malnutrition in utero, but that the disease has " attacked " the infant only during or after birth. On the other hand, many of the cases of intraventricular haemorrhage were probably "ill" for some time before delivery.

\section{Lesions of Mature Infants}

Trauma.-Kærn (1960) stated that the larger the foetus the higher the incidence of death during the birth and the smaller the foetus the higher the incidence of death after birth. A comparison of the stillbirths and neonatal deaths with cerebral birth trauma in the present series has shown that the stillbirth babies are, on the whole, larger for their gestation than babies dying neonatally. There are at least two possible explanations. Firstly, at each gestation there is a normally distributed population which suffers the insult-that is, trauma-a proportion of which die before delivery, and that those who survive the birth process are less likely to die if they are not initially growthretarded. The second theory would postulate that the baby that is growth-retarded is more likely to suffer the insult, but that the bigger baby, though less likely to receive the insult, is more likely to die immediately if it does receive it.

Asphyxia.-Conversely, it would appear that the baby dying of asphyxia during the second stage of labour is on average larger than those succumbing during the first stage. This suggests that the baby which is in "distress" before labour begins, finding the process of labour to be the "last straw," succumbs rapidly, whereas the larger better-nourished infant would be likely to die only if a severely asphyxiating condition arose (such as prolapsed cord), and this is more likely to occur during the second stage of labour.

Intrauterine Pneumonia.-It is also interesting that the mean birth weights of the cases with intrauterine pneumonia are insignificantly different from those of the controls, whereas the cases with extrauterine pneumonia are smaller. Hence probably the infants who acquire the infection in utero succumb regardless of their size, whereas later it would seem to be mainly the infants who were already growth-retarded that are most likely to die.

Extrauterine Pneumonia, Haemorrhagic Pneumonia, and Massive Pulmonary Haemorrhage.-It is shown above that the cases of massive pulmonary haemorrhage, like those of no cause found, presented among babies who were, on average, very definitely growth-retarded, a result previously reported by Butler (1965) and Hutchison (1967). The lesions are therefore apparently most prevalent among babies who have suffered from malnutrition in utero, and who were unable to cope with extrauterine life. It could be postulated that their resistance was low to any form of nutritional or other imbalance and that their ability to adapt themselves to circumstances was impaired. It has been found, for example, that massive pulmonary haemorrhage occurs among babies suffering from cold injury (Mann and Elliot, 1957). It also seems likely from the present data that a similar background of foetal starvation or " distress" is often found among mature babies dying from haemorrhagic pneumonia, and to a certain extent, extrauterine pneumonia. At necropsy many of the babies with these lesions are found to have typically small-for-dates morbidity: relatively small thymuses and livers for their gestation, together with a normalsized brain (Gruenwald, 1965), and hence a high brain-overliver ratio (Butler, 1965).

The present paper was prepared while I was in receipt of a grant from the National Fund for Research into Crippling Diseases. I am also grateful to the Executive Committee of the National Birthday Trust Fund for permission to use the data of the British Perinatal Mortality Survey, and to Professor C. A. B. Smith for much helpful advice.

\section{REFERENCES}

Ahvenainen, E. K. (1953). Annales Medicinae Fenniae, Suppl. No. 17, $42,1$.

Avery, M. E. (1953). The Lung and its Disorders in the Newborn Infant, 2nd ed. Philadelphia, Saunders.

Benirshke, K., and Driscoll, S. G. (1967). Pathology of the Human Placenta. New York, Springer.

Butler,.N. R. (1965). In Gestational Age, Size and Maturity: Clinics in Developmental Medicine, No. 19, edited by $M$. Dawkins and B. MacGreggor, p. 74. London: Heinemann, for the Spastics Society.

Butler, N. R., and Alberman, E. A. (1969). Perinatal Problems: the Second Report of the 1958 British Perinatal Mortality Survey. Edinburgh, Livingstone.

Butler, N. R., and Bonham, D. G. (1963). Perinatal Mortality : the First Report of the 1958 British Perinatal Mortality Survey. Edinburgh, Livingstone.

Dawkins, M. (1965). In Gestational Age, Size, and Maturity: Clinics in Developmental Medicine, No. 19, edited by $M$. Dawkins and B. MacGreggor, p. 33. London, Heinemann, for the Spastics Society.

deSa, D. J. (1969). Fournal of Obstetrics and Gynaecology of the British Commonwealth, 76, 148.

Dolezalova, V., and Dolezal, A. (1967). In Intra-uterine Dangers to the Foetus, edited by J. Horsky, Z. K. Stembera, I. R. Merkatz, and K. J. Dennis, p. 532. Amsterdam, Excerpta Medica Foundation.

Fairweather, D. V. I., Anderson, G. S., Bird, T., Russell, J. K., Millar, D. G., and Pearcy, P. A. M. (1966). Lancet, 1, 140

Fedrick, J., and Butler, N. R. (1969a). Certain Causes of Perinatal Death: II, Intraventricular Haemorrhage. In preparation.

Fedrick, I., and Butler, N. R. (1969b). Certain Causes of Perinatal Death: I, Hyaline Membranes. In preparation.

Gruenwald, P. (1963). Biologia Neonatorum, 5, 215.

Gruenwald, P. (1965). In Gestational Age, Size and Maturity: Clinics in Developmental Medicine, No. 19 , edited by $M$. Dawkins and B. MacGreggor, p. 66. London, Heinemann, for the Spastics Society.

Hutchison, I. H. (1967). Practical Paediatric Problems, 2nd ed. London, Lloyd-Luke.

Kærn, T. (1960). Acta Obstetrica et Gynecologica Scandinavica, 39, 392.

MacGillivray, I. (1965). In Gestational Age, Size and Maturity : Clinics in Developmental Medicine, No. 19, edited by M. Dawkins and B. MacGreggor, p. 42. London, Heinemann, for the Spastics Society. Mann, T. P., and Elliott, R. I. K. (1957). Lancet, 1, 229.

Mitchell, R. G., and Farr, V. (1965). In Gestational Age, Size and Maturity: Clinics in Developmental Medicine, No. 19, edited by M. Dawkins and B. MacGreggor, p. 83. London, Heinemann, for the Spastics Society.

North, A. F., jun. (1966). Pediatrics, 38, 1013.

Ounsted, M. (1965). Developmental Medicine and Child Neurology, 7, 479.

Räihä, C. E. (1967). In Intra-uterine Dangers to the Foetus, edited by J. Horsky, Z. K. Stembera, I. R. Merkatz, and K. J. Dennis, p. 335. Amsterdam, Excerpta Medica Foundation.

Schutt, W. (1965). In Gestational Age, Size and Maturity: Clinics in Developmental Medicine, No. 19, edited by M. Dawkins and B. MacGreggor, p. 1. London: Heinemann, for the Spastics Society.

Smith, C. A. (1947). Fournal of Pediatrics, 30, 229.

Stallworthy, J., and Bourne, G. (1966). Recent Advances in Obstetrics and Gynaecology, 11 th ed. London, Churchill.

Wade-Evans, T. (1961). Archives of Diseases in Childhood, 36, 293.

Walker, J. (1965). In Gestational Age, Size and Maturity: Clinics in MacGreggor, p. 36. London, Heinemann, for the Spastics Society. 